International Journal of Linguistics, Literature and Translation

ISSN: 2617-0299 (Online); ISSN: 2708-0099 (Print)

DOI: $10.32996 / \mathrm{ijllt}$

Journal Homepage: www.al-kindipublisher.com/index.php/ijltt

\title{
A Qualitative Investigation on the Role of Social Media in Intercultural Communication Competence: The Moroccan Diaspora in Canada as a Case-Study
}

\author{
Fatima Zahraa Boutabssil 8 (D) \\ Department of English Language and Tofail University-Kenitra, Morocco \\ $\triangle$ Corresponding Author: Fatima Zahraa Boutabssil, E-mail: Boutabssil@hotmail.fr
}

ARTICLE INFORMATION ABSTRACT

Received: June 02, 2021

Accepted: July 05, 2021

Volume: 4

Issue: 7

DOI: $10.32996 /$ ijllt.2021.4.7.4

\section{KEYWORDS}

Social media, social media use, intercultural communication competence, Moroccan diaspora
This paper aims to investigate how Moroccan migrants established in Canada utilize social media to improve their intercultural communication competence. It employs the exploratory sequential design based on the use of semi-structured interviews followed by a questionnaire. The results show that before migration, social media played an important role in providing the migrants with preliminary knowledge about the host culture via YouTube. Social media also facilitated communication with Canadians via Facebook. After migration, social and direct interaction was proven to be more effective in developing the participants' ICC. As such, social media only played an informative role, whereas much of the participants' intercultural knowledge, skills, attitudes, and awareness were developed from face-to-face communication. The study concludes that no matter how important social media can become, improving intercultural communication competencies cannot take place independently from face-to-face interaction.

\section{Introduction}

Intercultural communication can be seen as the process of interaction between individuals with different cultural backgrounds. Stockinger (2010) looks at it as the direct or mediated interaction between people belonging to different cultures, possessing different references, beliefs, values, traditions, histories, and languages. This means that intercultural communication involves the exchange of information that is loaded with socially and culturally constructed messages. Therefore, in the process of interaction, misunderstandings can take place, especially if the communicators are not acquainted with one another's language, traditions, values, and principles. Furthermore, misunderstandings do not only occur at the level of verbal communication. As body language constitutes another form of interaction, misunderstandings can occur at the level of the non-verbal messages, too. Therefore, developing the appropriate knowledge, competence, awareness, and skills is very important for communicators to interact effectively.

In a highly digitalized world, developing these skills has become an easy task. With the advent of social media networks, having contact with people from the other side of the world is only a keyboard-click-away. Furthermore, these networks have not only facilitated contact of people from different countries but have also enabled them to develop the appropriate methods and procedures to communicate effectively. Scholars have qualified the ability to communicate with individuals from different social and cultural backgrounds as intercultural communication competence.

Previous studies in the field, namely "the Impact of Social Media on Intercultural Communication Competence of Chinese People in Sweden" by Lui (2019) as well as the study by Luthfia (2019) entitled "The Role of Social Media in Improving Intercultural Communication Competence: a Comparative Study of European Students in Indonesia and Indonesian Students in Europe" focused on how international students utilize social media to improve their knowledge, skills, attitudes, and awareness of the host culture. In Morocco, no studies have yet been produced on how social media can be helpful in developing Moroccan migrants' ICC. Therefore, this study aims to explore the views and opinions of Moroccan migrants in Canada on the extent to which social media

K C AL-KINDI CENTER

$R$ DFOR RESEARCH AND DEVELOPMENT

Your gateway to world-class research

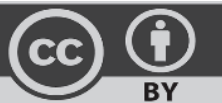

Published by Al-Kindi Center for Research and Development, London, United Kingdom. Copyright (c) the author(s). This open access article is distributed under a Creative Commons Attribution (CC-BY) 4.0 license 
contributed to the development of their intercultural communication competence. Thus, the central question that this paper tries to answer is as follows:
$\checkmark$ To what extent does social media improve the intercultural communication competence of Moroccan migrants living in Canada?

\section{Literature review}

Arasaratnam and Doerfel (2005, as cited in Liu, 2019) define intercultural communication competence as the ability to interact effectively and appropriately with people of different cultural backgrounds ( $p$ : 4). Scholars have discussed various models of intercultural communication competence, namely Deardorff, Byram, Bennett, and Fantini (Liu, 2019). They all agree that intercultural communication competence lies in the principles of cultural knowledge, respect, and developing skills to deal with intercultural encounters based on that knowledge (Günçavdi \& Polat, 2016). For this paper, Fantini's model of intercultural communication competence will be embraced as a framework of reference.

Initially, Fantini's model of intercultural communication competence is comprised of four different dimensions as shown in the figure below (Fantini, 2007):

Figure 1: Dimensions of Intercultural Communication Competence

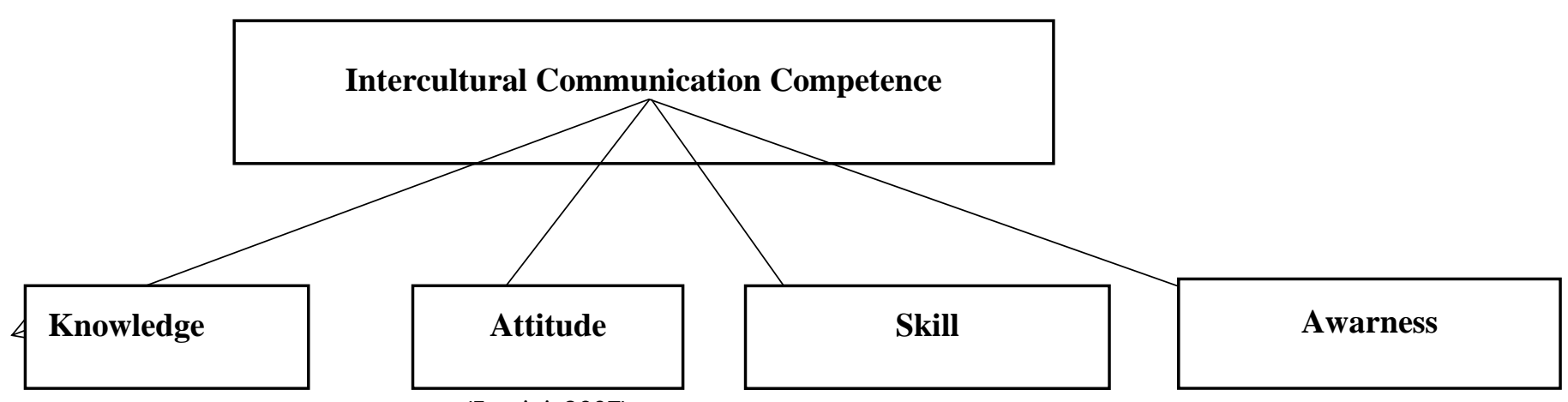

(Fantini, 2007)

Intercultural knowledge refers to an individual's skills to gain knowledge about one's own culture or another culture with which one interacts (Byram 2000 as cited in Liu, 2019). Similarly, Deardorff (2010, as cited in Gunçavdi \& Polat, 2016) defines it as the competence to have information about a specific culture (p: 41) and Fantini (2000, as cited in Liu, 2019) looks at it as knowing the hosting culture. Intercultural attitude is identified as openness, curiosity, and interest in different cultures (Deardorff, 2006). In addition to these, being risk-oriented, respecting differences, and having empathy are other intercultural attitudes (Odgers, 2009 as cited in Günçavdi \& Polat, 2016). Intercultural skill is referred to as one's ability to listen, observe, interpret, analyze, and evaluate people from other cultures and finally relate oneself to other cultures (Deardorff, 2006, as cited in Lui, 2019). Marin and Nakayama (2004) claim that learning a foreign language, listening, information gathering, and problem-solving can be examples of intercultural skills, while Fantini (2000, as cited in Gunçavdi \& Polat, 2016) identifies it as the intercultural behavior and states that it can be affected by the other aspects. Intercultural awareness is seen as one's ability to see the similarities and differences between one's culture and the other from a critical point of view (Byram, 2000). Therefore, Fantini's dimensions can be seen as one's ability to successfully experience acculturation, developing a sense of cultural sensitivity, and being able to expose and reflect this openness and adaptation in everyday communication.

Previous studies done in this area have mostly looked at how international students use social media to improve their ICC. However, their findings can still be used since the present study takes the Moroccan diaspora as part of the international community established in Canada. In this context, Luthfia, et al. (2019) found that social media has played an important role in improving international students' intercultural communication competence, although this latter cannot be developed independently from social interaction. A cross-cultural analysis was performed between Indonesian students living in the UK and English students living in Indonesia. Also, Liu (2019) conducted a similar study on Chinese students living in Sweden. Their studies produced the following results:

\section{Developing intercultural knowledge through social media:}

At the level of intercultural knowledge, European students established in Indonesia obtained most of their information and insights into the Indonesian culture from Instagram and Facebook. According to the study, most students learned about the daily lives of Indonesians from pictures and conversations posted on Facebook. They could collect information on the Indonesian lifestyle from 
photos uploaded by their Indonesian friends about interesting places, foods, clothes, and events, including tips to adapt to the local culture during their stay in Indonesia and the same applied for Indonesian students in the UK (Luthfia, et al., 2019).

Likewise, Liu (2019) demonstrates through his study that the Chinese students in Sweden showed high favorability towards the role of social media in developing their knowledge through four aspects, namely deep knowledge of the Swedish culture, knowledge of its norms and taboos, knowledge about the socio-political factors that shape the Swedish culture and the ability to compare various behavioral patterns between the mother culture and the host one. Thus, the study showed that the students' intercultural knowledge increased and was improved through social media.

\section{Developing intercultural attitudes through social media}

Luthfia, et al. (2019) found that social media did not play a significant role in fostering students' sense of cultural acceptance and tolerance as much as face-to-face conversations did. The findings also showed that Indonesian students had already equipped themselves with values of openness and developed attitudes of being non-judgmental towards other cultures before joining the cultural exchange program. Social media had only reinforced and improved these values by reading commentaries, conversations, and photos uploaded by the participants' British friends. This helped them become more open-minded to accept differences (APA, 2019).

Liu's study (2019) showed that social media has enabled the Chinese students in Sweden to improve their intercultural attitudes, namely through learning about the Swedish culture and language, communicating in Swedish and behaving appropriately, showing interest in new cultural aspects, and understanding differences in the behaviors, values, attitudes, and styles.

\section{Developing intercultural skills through social media}

At the level of intercultural skills, different results were obtained. For instance, concerning the Indonesian students in the UK, social media was not helpful in developing knowledge and cultural skills (Luthfia, et al., 2019). Facebook and Instagram were helpful to only improve their ability to observe, interpret, analyze and evaluate their relationships with Indonesian friends and culture (APA, 2019). For the British students in Indonesia, social media developed their cultural flexibility which facilitated their interaction in face-to-face meetings. Social media also helped them learn about popular topics and how to react and respond in conversations (APA, 2019).

Liu (2019) found, in his study, that social media enabled the Chinese students in Sweden to develop skills to improve their styles and personal interaction, employ strategies to learn about the Swedish culture and language, demonstrate flexibility in interacting with others and develop the ability to resolve cross-cultural conflicts and misunderstandings.

\section{Developing intercultural awareness through social media}

The same study conducted by Liu (2019) demonstrated that social media contributed to developing the awareness of Chinese students in Sweden. Almost all participants in the study agreed that social media has enabled them to develop intercultural awareness in terms of understanding the cultural differences inherent within the Swedish culture, awareness in terms of the Swedish values, the differences between the Swedish and Chinese cultures, and eventually the extent to which social media has contributed to the intercultural development of the participants.

\section{Methodology:}

\subsection{Research design}

This paper is fundamentally qualitative. However, it adopts the exploratory sequential design based on the use of an extensive exploratory investigation followed by a quantitative phase. The researcher sought that a mixed-method approach would be the most appropriate. The use of semi-structured interviews allowed a deep investigation of the concepts under study. Questionnaires were used to reach a larger population.

\subsection{Sampling and participants}

The population of this study is made up of Moroccan diaspora established in Canada. The respondents were selected based on specific determined criteria to best serve the purpose of this study. Therefore, the participants selected meet the following characteristics: 1) Participants are Moroccans who are currently living in Canada/2) Participants are currently using social media/3) Participants used social media before moving to Canada. Therefore, participants who claimed to move to Canada before social media existed were not selected. 
In the qualitative phase, 10 participants were interviewed, 4 females and 6 males. Their ages range between 30 and 50 years old and all of them live in Montreal. In the quantitative phase, 72 participants answered the questionnaires. They are all Moroccans who currently live in Canada, they all use and have daily access to social media.

Figure 2: Demographics of participants in the quantitative phase

\begin{tabular}{|l|c|c|}
\hline \multirow{2}{*}{ Item } & Range & Numbers \\
\hline \multirow{2}{*}{ Gender } & Female & 30 \\
\cline { 2 - 3 } & Male & 42 \\
\hline \multirow{2}{*}{ Age } & $21-30$ & 22 \\
\cline { 2 - 3 } & $31-40$ & 20 \\
\cline { 2 - 3 } & $41-50$ & 12 \\
\cline { 2 - 3 } & $51-60$ & 8 \\
\cline { 2 - 3 } & $61-70$ & 10 \\
\hline
\end{tabular}

\subsection{Data collection methods \\ Qualitative phase \\ Semi-structured interviews}

Semi-structured interviews are used in the first phase of this paper. Interviews allow the researcher to have an in-depth investigation of the concepts explored (Creswell, 2014). Even with a question guide, semi-structured interviews allow both the researcher and participants to broaden the discussion which enables the interviewer to gain a deeper understanding of the issues under study (APA, 2014). In this paper, the use of semi-structured interviews allowed the researcher to understand the role of social media in ICC in the case of Moroccans residing in Canada. All of the interviews were conducted online via Google Meet and Zoom applications.

\section{Quantitative phase}

\section{Questionnaires}

The second phase aims to explore the extent to which social media helped the Moroccan diaspora improve their ICC. For that, a cross-sectional survey design was employed. According to Creswell (2014), survey designs are used to describe trends, explore attitudes, beliefs, and opinions about specific concepts or issues. In the present study, the researcher used a descriptive questionnaire based on Fantini's (2007) Intercultural Competence Scale.

\section{Examination of the sub-variables used in the paradigm of ICC}

This section looks at the sub-variables to be used in this study. The sub-variables were derived from Fantini's intercultural competence scale (Fantini, 2007).

Figure 4: The sub-variables used in the study

\begin{tabular}{|c|c|}
\hline Variables & Sub-variables \\
\hline 1. Intercultural knowledge: & $\begin{array}{l}\text { - Through social media, I discover the norms, values, } \\
\text { and taboos inherent in the Canadian culture. } \\
\text { - Through social media, I am able to learn about } \\
\text { interesting places, food, clothes, and lifestyle in the } \\
\text { Canadian culture. } \\
\text { - Through social media, my knowledge of the } \\
\text { Canadian culture has deepened. } \\
\text { - Through social media, I could discuss and contrast } \\
\text { behavioral patterns in my own culture with those in } \\
\text { Canada. }\end{array}$ \\
\hline 2. Intercultural skills: & $\begin{array}{l}\text { - Through social media, I develop my language skills } \\
\text { in French and English. }\end{array}$ \\
\hline
\end{tabular}




\begin{tabular}{|c|c|}
\hline & $\begin{array}{l}\text { - Through social media, I am able to understand and } \\
\text { use specific expressions inherent in the Canadian } \\
\text { culture appropriately. } \\
\text { - Through social media, I am able to understand and } \\
\text { use body language appropriately. } \\
\text { - Through social media, I developed cultural } \\
\text { flexibility when interacting with people from Canada. }\end{array}$ \\
\hline 3. Intercultural attitudes: & $\begin{array}{l}\text { - Through social media, I was able to develop an } \\
\text { interest in the different particularities of Canadian } \\
\text { culture. } \\
\text { - Thanks to social media, I have become more open, } \\
\text { tolerant, and accepting towards the Canadian culture. } \\
\text { - Thanks to social media, I understand differences in } \\
\text { behaviors and attitudes. } \\
\text { - Thanks to social media, I try to communicate in } \\
\text { French and English and behave in appropriate ways. }\end{array}$ \\
\hline 4. Intercultural awareness: & $\begin{array}{l}\text { - Through social media use, I am aware of the } \\
\text { diversity in Canadian culture. } \\
\text { - Through social media, I am aware of the strategies } \\
\text { that enabled me to be culturally and socially accepted } \\
\text { by the Canadian community. } \\
\text { - Through social media, I am aware of my own } \\
\text { intercultural development. } \\
\text { - Through social media, I am aware of the differences } \\
\text { and similarities between the Moroccan and Canadian } \\
\text { cultures. }\end{array}$ \\
\hline
\end{tabular}

(Fantini, 2007)

\section{Data analysis procedures \\ Qualitative phase}

For the qualitative phase, an interpretive thematic analysis is employed, as suggested by Creswell (2014). The interpretation of the findings is based on what was discussed in the literature review.

\section{Quantitative phase}

The levels of measurement used in this study decide upon the data analysis procedures to be employed. Dichotomous, multiplechoice, and open-ended questions are considered nominal categories.

Therefore, for nominal categories, descriptive statistics represent the most suitable procedures for analysis. It is also appropriate because it will enable the researcher, through the use of percentages to generate data on the attitudes and opinions of participants. The quantitative data will be displayed in the form of bar charts, pie charts, and percentages. The presentation of the data extracted from both phases will take place simultaneously in the form of themes.

\section{Findings and discussion}

The findings of the interviews conducted revealed three themes; purposes of social media use, social media use prior to Canada, and the role of social media in intercultural communication competence. The themes were taken into further investigation in the quantitative phase through the descriptive questionnaire administered to the participants. The findings of each theme will be supported by the results of the survey.

\section{Purposes of social media use}

The social media networks mostly used by the Moroccan diaspora established in Canada were mainly Facebook, Whatsapp, Youtube, and Instagram. Interviews with the participants revealed that Facebook and Whatsapp were mainly used to communicate with their family members and friends in Morocco as well as keeping in touch with people they cannot communicate with face-toface. All participants claimed that they also use Facebook and Youtube to get new information and enrich themselves. Others 
consider social media as a source of entertainment. However, some participants stated that Facebook is also used as a means of discovering other cultures. Participant $A$ states in this regard that,

"...Through Facebook, I can communicate with my friends and family in Morocco. At the same time, Facebook and Youtube provide me with information on multiple fields; getting new information has become easier through social media... Therefore, the purpose of using social media, from my experience, is to feed my curiosity and inquisitiveness to discover new cultures and traditions and get new information and news..."

Participant B puts it this way, she mentions that,

"I use Facebook messenger to communicate with my family in Morocco. It is very expensive to call a family member in Morocco from Canada; we cannot afford it. Messenger and Whatsapp offer free services. So I use both of them to communicate with my family, my teachers, and my old colleagues in Morocco...Communication has become much easier. I guess we are truly lucky to live in the 21st century when everything has become easier through social media".

As far as Youtube is concerned, participant C states that through watching Youtube channels, he is able to gather information about other cultures and countries before deciding to visit. He says that,

"For me, Youtube is not only an important source of information. As I am very passionate about traveling, I use Youtube to discover interesting places to visit not only in Canada but in the whole world".

The results of the survey show that social media are used for other purposes namely finding job opportunities, sharing points of view on different topics, finding love, and doing business.

Thus, this study revealed that the most popular social media networks used were Facebook, WhatsApp, Instagram, and Youtube. The findings of the interviews also showed that social media is primarily used to maintain relationships with family and friends in Morocco more than with the people of the host country. This goes in line with the results found in Liu's study on the impact of social media on Chinese students' ICC. His study revealed that most students used social media to communicate with their family and friends in their country of origin more than to develop new social networks or to know new people. Luthfia, et al. (2019) also found in this context that Indonesian students resorted to SMS or telephone to contact people they know in the host country and they only share Whatsapp with the people they feel comfortable with. This echoes the findings of the present paper as most participants claimed to use phone calls to keep in touch with the people they know in Canada. The outcome of the interviews also revealed that WhatsApp is mostly used with the people with whom they communicate more frequently, while Facebook was used with cousins and family members with whom communication takes place less regularly.

These findings echo Sawyer's claim that social media connects students, in this case, migrants, with their countries of origin as it provides an outlet to stay in touch with their friends and family in their home country. This also echoes the findings of Chen and Choi (2011) who found through their study on Chinese migrants' adaptation to the local culture that they use social media to communicate with their family and friends more than with the local people. Liu (2019), on the other hand, found that Chinese students communicate with their Swedish friends via social media. Some even convinced their Swedish friends to install Chinese social media to keep in touch with each other.

The findings of the interviews also revealed that as far as getting new information is concerned, this study proved that Facebook constitutes a major source of staying up-to-date vis-à-vis the news and development in Canada. A participant, for instance, claimed that he got to know about a document he needed to fill for the government through Facebook. Luthfia, et. al. (2019) found that for European students in the UK, this is accomplished more through face-to-face interaction.

\section{Social media use prior to Canada}

Another theme emerged in the data collection process represented in the use of social media before migrating to Canada. The researcher aimed to find out whether social media had helped the participants have preliminary knowledge about Canada and the Canadian culture before migrating to the country. In question 3 of the survey, participants were asked if social media had facilitated their contact with Canadians before moving to the country. Their responses were as follows: 
Figure 5: Social media use prior to Canada

\section{Before migrating to Canada, did social media help you have contact with Canadians?}

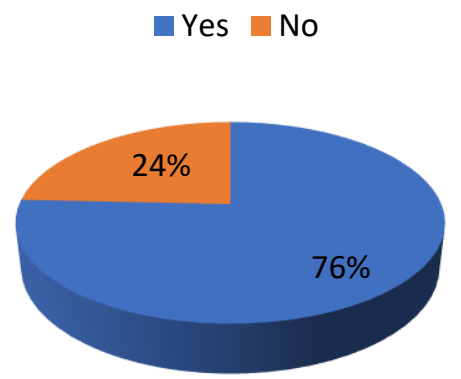

The findings revealed that $76 \%$ claim having had contact with Canadians prior to moving there, while $24 \%$ claim the opposite, as shown in the figure above. To explore more on this, participants were asked, in question 4, to explain how social media helped them get preliminary knowledge about Canada and the Canadian culture. The participants who checked "No" in question 3 were not allowed to answer this question.

As question 4 was open-ended, its results were classified into two categories: social media played an important role in providing enough knowledge about Canada, and social media partially contributed to providing knowledge as it was not the main source of information.

In the first category, participants claim that Facebook allowed them to make friends, and Facebook pages allowed them to stay up-to-date vis-à-vis the country. They stated that,

"I used to add people from Canada in my Facebook, I made e-friends. Through the daily exchange, I started to learn more about their culture, how they think, how they live, how they react. I guess social media enabled me to observe and evaluate these things".

"I got to know about Canada through Facebook by subscribing to Canadian Facebook groups and pages. I used to receive daily updates about the events, weather, lifestyle, and news about the city I had intended to settle in".

"Social networks played a role in my discovery of the host country and made me forge friendships before and after my arrival to Canada. Also, they allowed me to have all kinds of information I need in my daily life".

Other participants claim that social media were behind their migration to Canada, they state that,

"It is through social media that I started thinking about migrating to Canada, I was fascinated about Canada and the Canadian lifestyle".

"It is thanks to social networks that I was able to discover the possibility of migrating to Canada".

"Through Facebook, I was able to have friends who encouraged me to start my migration process to Canada".

Other participants claim that social media helped them integrate into the Canadian society easily, they say that,

"Before arriving in Canada, I was able through social networks to make friendships with several members of this community. This prevented me from feeling disoriented after my arrival. I had a preliminary idea of the country, its habits, culture, and life in general". 


\begin{abstract}
"Before migrating to Canada, I used to do a lot of research on what life looks like in Canada in all its aspects namely culture. It is very important for me because I am an outgoing person, I wanted to discover about local restaurants, local food, pubs, bars..."
\end{abstract}

Other participants stated that Youtube was another source of their preliminary knowledge about the country, some claim that,

"I had the opportunity to discover the Canadian culture through Youtube videos"

"Social networks are a varied platform that allowed me to have everything I needed in terms of information through videos and different means of communication. All this allowed me to better frame my arrival here and to integrate into the society as quickly as possible".

"On YouTube, for example, you can consult several channels that showcase everything related to this country. I was also able to have friends who later became real friends who helped me integrate into Canadian society easily".

Some of the participants were students; they claim that social media helped them know about the many opportunities offered in the country, finding universities, and getting information about its educational system and culture.

In the second category of results, participants stated that social media had contributed to their knowledge although it was not the main source.

Participant A claims that,

"Social media has helped me a lot with that, but I will also say that as I was in the process of preparing my migration application, I read many books about Canada, its culture, provinces, social, economic, and political systems, so I developed a preliminary knowledge that was then proved to be correct through research I had conducted on social media namely Google...Therefore, I believe social media partially contributed to this knowledge and was not the only source of information I relied on".

According to Participant B, social media only provided superficial information on the country. Face-to-face interaction was proven, according to him, to be more effective. He states that,

"There is a difference between discovering things through social media and going through things in a face-to-face environment. I had discovered different things about Canada before coming here, but when I moved, I discovered things that I did not know about through social media. Also, there are things that I had discovered through social media that were not true... For instance, having access to different social media networks, you find out that Canadians promote the image of their country in a good way, so you feel it's paradise on earth, they have a good marketing technique to do that. Therefore, when I was in Morocco, reading about Canada on social media made me fascinated by the country. Moving here, I found out that there are things missing... things they don't talk about, so one is very likely to go through a shock. Here, social media does not play an appropriate role, it can sometimes be misleading..."

Participant B is of the same view. She mentions that in addition to reading books about Canada and the Canadian culture, social media helped to provide information about the country. She also states that face-to-face interaction was more effective. She gives an example and states that,

"Seeing Facebook and Instagram posts, I was convinced that Canada is a democratic and developed country. Certainly, this is the case. However, moving here and having to deal with people on a daily basis, I discovered that Arabs and Muslims are subject to racism. There are things I knew of neither through social media nor through reading books. I did that when I came here and experienced things through face-to-face and direct interaction. I guess social media and face-to-face interaction have a complementary role. For me, social media enabled me to communicate with the Moroccan community already established in Montreal. However, a huge part of my knowledge was achieved through face-to-face interaction more than with social media"

The results of this question showed that social media's role in providing knowledge about the country and the Canadian culture could be seen in two different ways; social media was totally seen as the main motivation behind some participants' migration to the country in terms of the amount of information it provided while others looked at it as a secondary source of information as it can sometimes present falsified and misleading data. In terms of communicating with Canadians prior to migration, most participants claim social media was helpful in making friends through Facebook. Liu (2019) confirms the opposite. She found that Chinese students did not get to communicate with their Swedish friends before moving to Sweden. Those results echo Sawyer's study on the impact of social media on intercultural adaptation (2012) who found that before international students arrived in the 
US, they had only a few contacts, including professors with whom they communicated through the mail. His study concluded that social media did not play a prominent role in developing participants' new relationships before moving to the US; however, it was still used to become more familiar with the culture through talking to their friends about the cultural experience. Therefore, the present study adds that social media contributed to Moroccan migrants' knowledge about Canada as a main source of information, while for others, it had partially contributed to that knowledge.

The findings of the interviews conducted also revealed that social media contributed to developing stereotypes on the country prior to migration. A participant claims that,

\section{"Before migrating to Canada, I had learned from my family already established here and through the social media that Canadian people are very individualistic and into themselves. I learned that via Facebook through reading their comments and posts. I used to observe their reactions among themselves and towards foreigners...this was confirmed when I first came here when I had to deal with locals..."}

In this case, social media helped to strengthen stereotypes about the country. The same participant claimed that social media helped him develop the same attitudes before migration which in turn allowed him to better adapt to the host culture. Another participant claims that social media reinforced the stereotype that all Canadians are accepting and tolerant. He states that "At least that's what I knew from Facebook and Youtube...moving here, I noticed that racism and ethnic discrimination is common in Canada...I personally experienced favoritism in my workplace...the opposite is disseminated through social media...". These findings echo Sawyer and Chen's study (2019) on the role of social media in intercultural adaptation, where social media was revealed to play a duality of roles vis-à-vis stereotypes. According to the study, some participants stated that social media strengthened stereotypes in the US while other participants claimed that social media reduced and weakened the stereotypes in the country.

\section{Social media and intercultural communication competence}

The last section of the survey aimed to explore the attitudes of participants towards the role of social media in improving and developing their ICC in terms of the dimensions discussed in Fantini's model of intercultural communication competence. Participants were asked to check either (agree), for confirming the role of social media in developing their ICC, "Social media partially contributed to developing this skill, I think face-to-face interaction is more effective" as a second option, and (disagree) for disapproving the role of social media in improving their ICC.

\section{Intercultural knowledge:}

In terms of the first dimension, survey results revealed the following findings:

Figure 6: Summary of findings (intercultural knowledge)

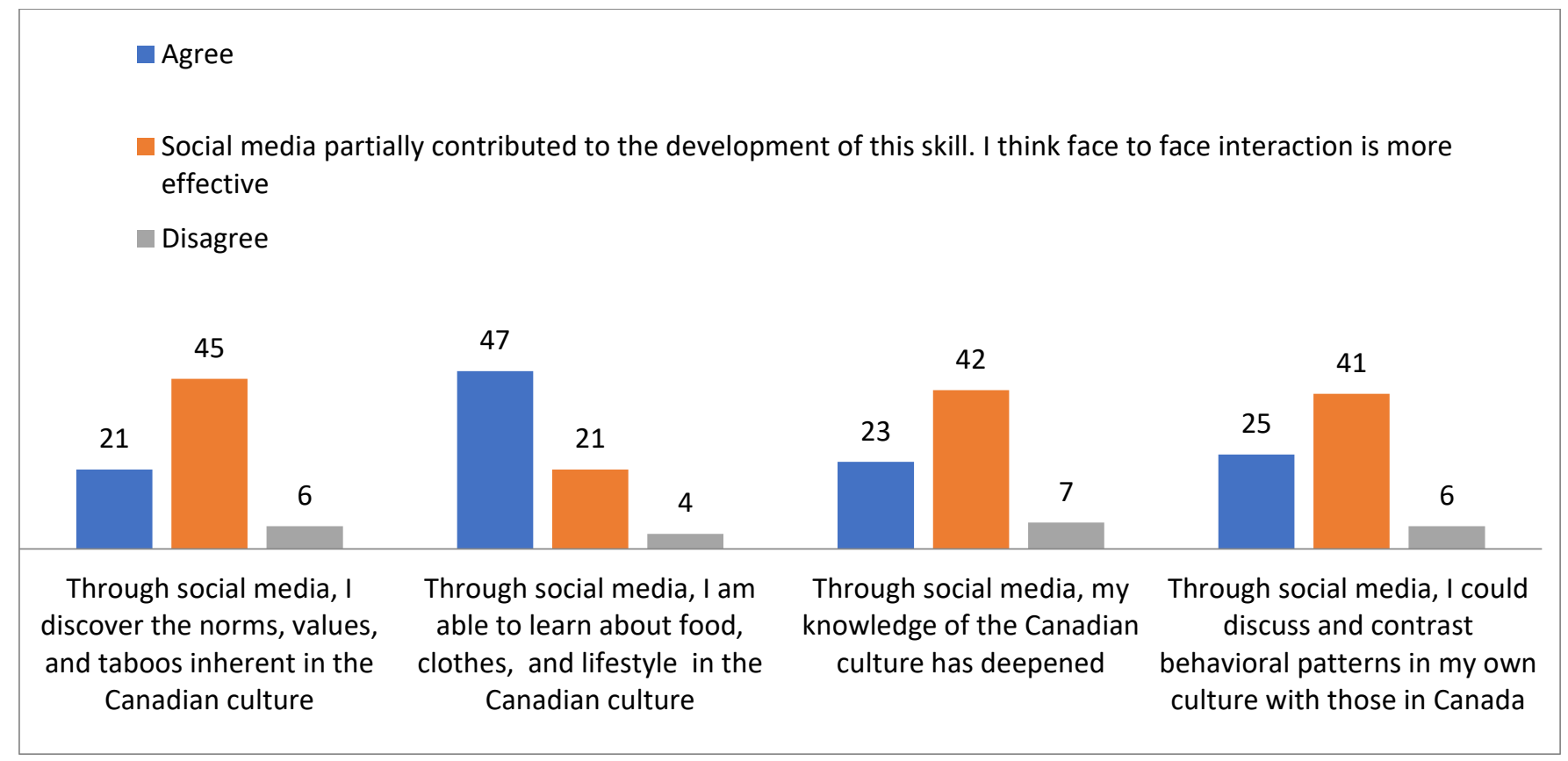


Social media was proven to play an important role in the second factor only where (47) participants claimed that social media played a central role in fostering their knowledge about the foods, clothes, and lifestyle of the Canadian culture. In this context, a participant claimed in one of the interviews conducted that, "If I want to find a restaurant to try and discover local food, I never ask my friends or colleagues to point one, rather, I go to Facebook, check different restaurants Facebook pages, read the reviews, the comments on people's experiences there. This is how I decide if I am going there or not. I believe Facebook helps you find the best option instead of wasting your time asking others".

In terms of learning about the clothing styles and lifestyle of the Canadian culture, another participant claims that "I think I discovered more about Canadian clothing styles through different Youtube videos. I subscribe to different Youtube channels, I like to stay up-to-date vis-à-vis what they wear, how they live, what they eat. I can say that I rely more on social media on this".

Participant C claims that "Concerning the clothing and lifestyle, I knew more about them through the pictures that my Canadian friends post on Facebook. This allows me to observe, evaluate and learn about their way of doing things..."

However, most participants claimed that social media partially contributed to the development of the other factors: [(Factor 1/ 45 participants), (Factor 3/42 participants), (Factor 4/ 41 participants)]. In the interviews conducted, a participant claims that "Social media, in this regard, give me a preliminary idea on the values, norms, taboos and all that concerns intercultural knowledge. Face-to-face conversations provide me with real knowledge as I get to interact with people directly".

The findings of this study concerning the role of social media in intercultural knowledge can be contrasted to previous studies done in this field. While the present study found that social media partially contributed to the migrants' deep knowledge, acquaintance with the values and norms of the Canadian culture, ability to discussing and contrasting differences and behavioral patterns between the host and mother culture, Liu's study (2019), in this regard, proved that participants showed a favorable view towards the role of social media in the above-mentioned factors. Similarly, Luthfia, et al. (2019) found that for the European students in Indonesia, social media played a prominent role in providing insights into the Indonesian culture through Instagram and Facebook.

Concerning knowledge about the lifestyle of the host culture, Luthfia's study (2019) showed that social media played an important role in providing information about interesting places to visit, food, clothes, and events which contributed to the European students' knowledge of the host culture which echoes the finding in this study.

\section{Intercultural skills:}

In terms of intercultural skills, in all four factors, most participants claim that social media partially contributed to developing their intercultural skills as shown below:

Figure 9: Summary of findings (intercultural skills)

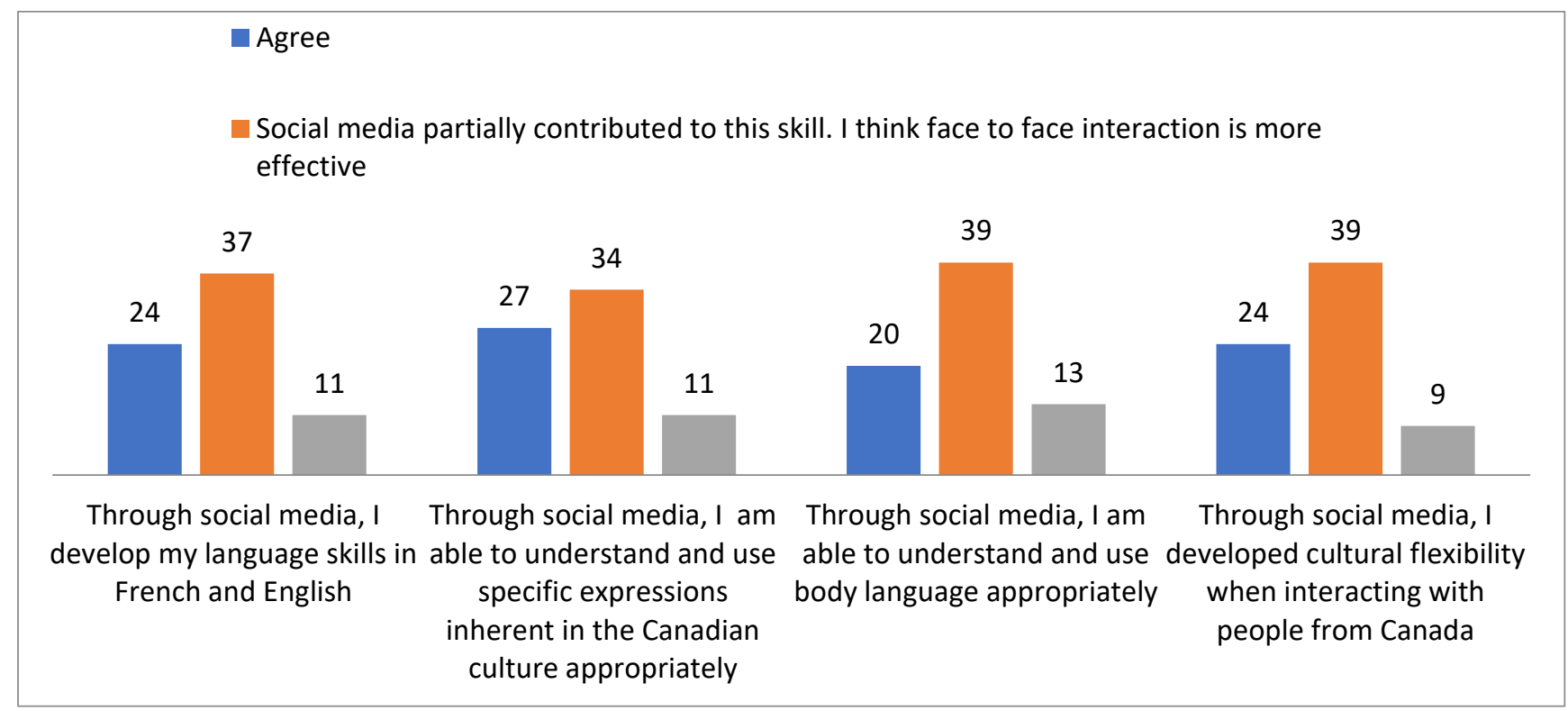


In the interviews, most participants claim that social media partially contributed to the development of their intercultural skills by providing basic information. For instance, in terms of non-verbal communication, participants learned about it through watching videos on Youtube and Facebook. The same participants claim that face-to-face and direct interaction was more fruitful. In this context, a male participant claims that,

"In my first job, my boss was a woman. In Morocco, normally, we do not make eye contact with women as a way of showing respect. The first time I had to talk to my boss, I avoided making eye contact to show that I respected her, but she felt offended and had to ask me about it. I knew, through this incident, that eye contact is important in Canada".

Another participant talked about the concept of personal space in Canadian culture. He stated that "In Morocco, it is totally fine to stand very close to others especially to people we appreciate being with, in Canada, this is totally unaccepted. Personal space is very important to make the person talking to you more comfortable. I discovered this through direct interaction with colleagues in my workplace".

Some other participants stated that, in terms of developing their language skills and use of cultural-specific expressions, social media partially contributed to the development of these skills as it was not the main source. In the interviews conducted, one participant explains that "When you live in a community where people use these expressions, you start to use them unconsciously with colleagues and friends. Being at the shopping mall, for instance, you hear people talk...this is how I learned to use cultural specific expressions". Another participant claims that "Social media was used to look for the meaning of the expressions and idioms I would hear people use every day".

In terms of cultural flexibility, a participant adds that face-to-face interaction was more effective in helping him being more flexible towards cultural differences. He states that,

"When I was in Morocco, I didn't accept that anyone would consume alcohol before my eyes, it's forbidden in my religion and it's just inappropriate because I was raised in a conservative family. Coming here, having to attend dinner parties, meetings, I was forced to sit around one table with people who drink. I think I became more flexible by going through this every now and then. Social media only shows you that in Canada, things are different. One does not really become flexible if they are not put in concrete situations like these".

The findings of the interviews and the survey show simultaneously that most participants agree that social media can only partially contribute to developing intercultural skills. Most participants would use percentages to showcase the role of social media. Most of them give $50 \%$ to the role of social media and another $50 \%$ to direct interaction.

Part of the results found in this paper echoes the findings of Luthfia's study (2019) where she concluded that European students obtained their language skills through direct communication. Concerning cultural flexibility, the same study found that Indonesian students in Europe acquired cultural flexibility by observing the British conversations in social media which helped them become flexible in face-to-face meetings. The present paper adds that in terms of intercultural skills, acquiring and learning how to use body language appropriately was mainly achieved through face-to-face interaction. In this case, the results of the interviews revealed that this is how participants learned to resolve cross-cultural conflicts and understandings when they arose. Liu (2019) found that social media played a major role in this regard.

\section{Intercultural attitudes}

In terms of the third dimension, the findings of the questionnaire revealed that most participants claim that social media partially contributed to developing their intercultural attitudes. 
Figure 10: Summary of findings (Intercultural attitudes)

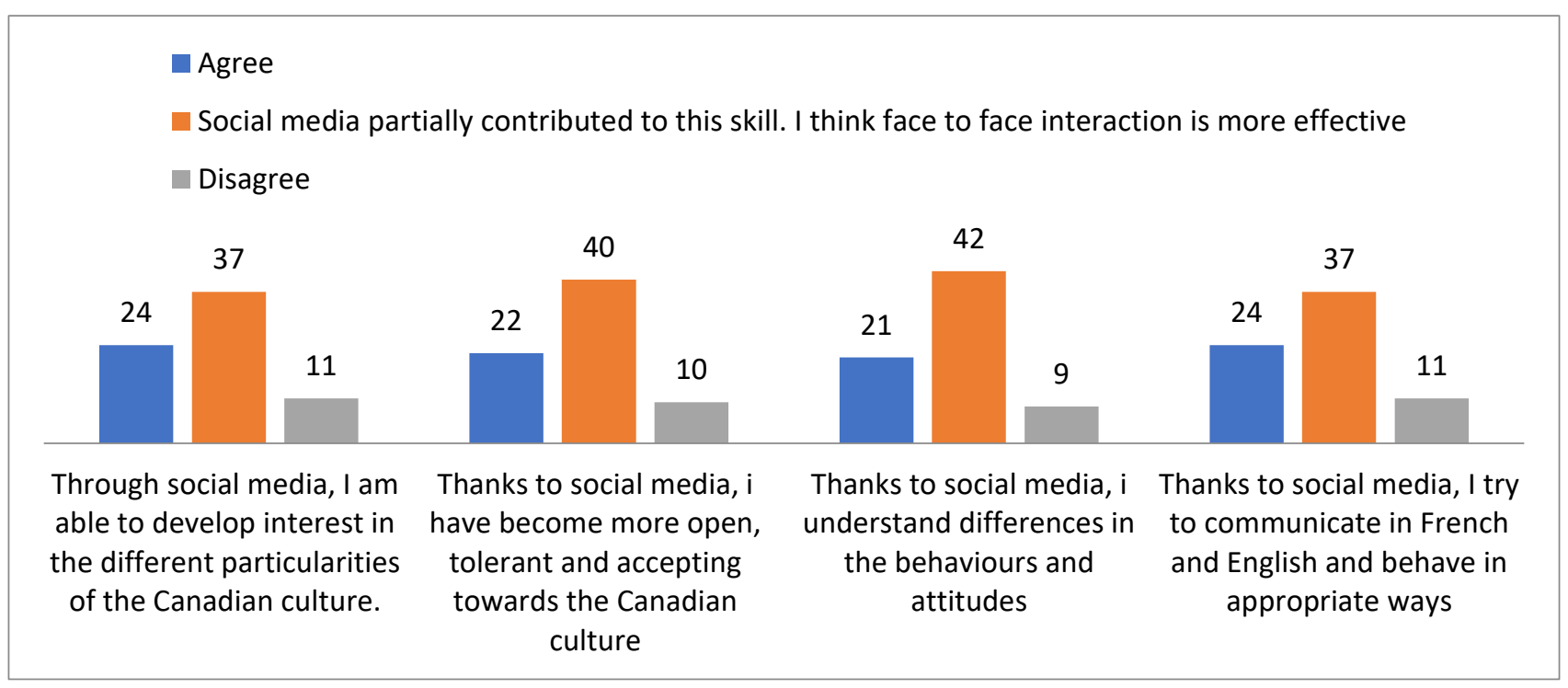

In terms of the first factor, (24) participants claimed that social media played an important role in developing their interest in the different aspects of the host culture while (37) participants claimed that social media partially contributed to that. In the interviews conducted, a participant revealed that he became interested in Canadian cuisine mostly through going to restaurants with friends. He states that "I got to taste a famous dish here called "poutine", I knew it through social media but it's only when a friend talked to me more about it that I decided to go to a restaurant and taste it".

In terms of developing tolerance, openness, and acceptance through social media, the survey results showed that the majority of participants (40) claimed that face-to-face interaction was more effective. In the interviews conducted, a participant explains that,

"Social media has an informative role. They let you know that for example tolerance is important, but it's only through face-to-face interaction that you can develop these attitudes. It also depends on the person, their degree of adaptability, their background, the extent to which they can become culturally flexible, so I will not say that social media helped me $100 \%$ in this area here nor can we consider that social media will help you grow or change. Social media informs you on different aspects, highlights the importance of being accepting especially in a melting pot culture but doesn't show you how to become tolerant".

This was confirmed with another participant who stated that "If one does not believe in openness and difference, if one is naturally ethnocentric, social media cannot help fight these aspects. These are personality traits that are difficult to change". Another participant claims that,
"I remember my boss was a lesbian, I know people with specific sexual orientations, homosexuals, so through interacting and living with those people, you become more accepting and tolerant. In Morocco, it's so inappropriate to deal with those people, but here, I learned that it's totally okay, even the government protects their rights. Through social media, what you know is that those people exist and that you should be tolerant but you never learn practically to be accepting. Face-to-face interaction is, therefore, more effective in this context; I learned to deal with people as "human beings" regardless of their sexual, religious or political orientations through direct interaction with them".

For the third factor, the findings of the survey show that (21) respondents claim social media played an important role in their understanding of the differences in behaviors and attitudes while (42) participants claim social media partially contributed to that. In the interviews, a participant gives the example of the "don't take it personally" expression that reflected Canadians' attitudes towards emerging problems, especially in professional environments. He states that "When I was in Morocco, I used to take things very personally... having problems with colleagues means cutting off relationships with them... when I came to Canada, I learned to be neutral...I used to read the expression "don't take personally" in people's Facebook posts and comments but I got to know what it really means when I started dealing with people in my workplace...".

Another participant talks about the concept of time in Canadian culture. He states that "In Morocco, it is fine to be late for an appointment, a Moroccan friend or a family member would never react negatively to that...In Canada, people are very likely to have 
a negative attitude to that...". The same participant claims that he got to know that punctuality is very important in Canada through social media but did not get to understand how important it really was until he was put in concrete situations.

In terms of the fourth factor, the survey results show that (37) participants claimed that social media partially contributed to their ability to communicating in the local languages while only (24) respondents claimed that social media played a pivotal role in this regard. In the interviews conducted, a participant explains that,

"For English per see, I try to communicate with my friends either through Whatsapp or Facebook in English to improve my level. However, at the same time, I like to practice face to face. I was working in an American Company in Montreal where almost everyone used to speak English so I learned a lot from them through daily face-to-face communication..."

Another participant adds that in terms of learning to behave appropriately,

"I think mainly through reading Facebook posts and comments, reactions, I observe how people react to certain problems or issues and I try to adopt the same attitudes, but it's also very important to consider the role of face to face interactions because nothing replaces physical communication. Through Facebook, I was able to know about these attitudes, but it's through directly communicating with people from the community that I was able to develop these attitudes thus learning to act and react appropriately".

The results of the interviews and the survey show that social media and intercultural communication competence play a complementary role in all the factors discussed above. We can conclude that social media partially contributed to developing intercultural attitudes while the role of face-to-face interaction was important for most participants. Liu's study proved otherwise. In terms of showing interest in new aspects of the host culture, learning to behave appropriately, and communicating in the host country's language, Liu (2019) found that social media played a prominent role in the three factors. The results of the present study echo Luthfia's findings in terms of developing attitudes of tolerance and open-mindedness towards other cultures. Her study showed that participants developed these qualities before migration which is also the case in this paper.

\section{Intercultural awareness:}

In the last dimension, the survey results show that most participants claimed that social media partially contributed to developing participants' intercultural awareness while face-to-face interactions were more helpful as shown in the figure below:

Figure 11: Summary of finding (intercultural awareness)

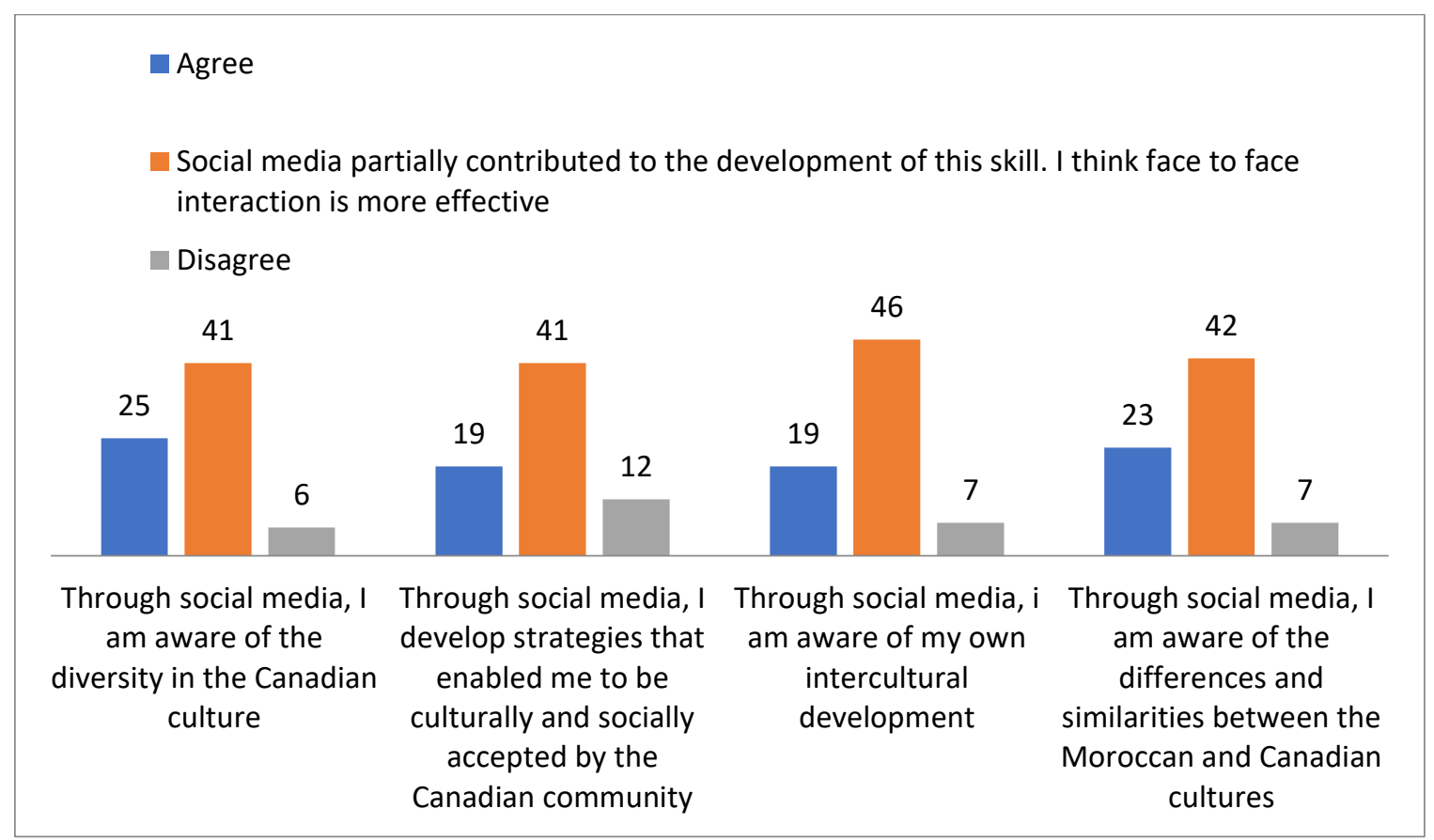


In terms of the first factor, "through social media, I am aware of the diversity in the Canadian culture", in one of the interviews, a participant claims that,

"I believe that social media only reinforced this awareness. When I was in Morocco, I learned about the culture first through reading books. When I moved to Canada, social media contributed to this awareness by providing more information. However, I believe that face-to-face contact and having to deal with Canadians daily, spending time with them and sharing things helped me improve my awareness of the different aspects of the Canadian culture".

Another participant claimed the same thing for the fourth factor "Through social media, I am aware of the similarities and differences between the Moroccan and the Canadian cultures". She states that,

"Social media orient you in this context, so through what you observe and see through the media, you link what you see to what you already know. From my own experience, through daily interaction with others, I was able to develop this awareness. I invite my Canadian friends over, I prepare Moroccan food, they get to taste it, they invite me back, and they serve Canadian food. I guess this is how I got to be aware of the differences and similarities between the Moroccan and Canadian cuisines".

For the second factor "through social media, I develop strategies that enable me to be culturally and socially accepted by the Canadian community", and the third factor "through social media, I am aware of my own intercultural development", the findings of the interviews and the survey revealed that, for both factors, participants claimed that social media only played an informative role on what the dos and don'ts are. Face-to-face was proven to be more effective as for instance, through pieces of advice given from friends and acquaintances, through direct observation and evaluation, they were able to develop strategies that facilitated their cultural and social integration in the Canadian community. Face-to-face interaction was also more effective in evaluating their intercultural development. The same was also proved through the results of the survey (Figure 11).

Thus, in terms of intercultural awareness, the results of this paper show that social media only partially contributed to the development of Moroccan migrants' awareness in all four factors. However, Luthfia's study (2019) revealed that in terms of developing awareness concerning cultural differences, social media was fruitful as students were able to learn about these differences through commentaries, photos, and posts uploaded by local students. Liu's study confirmed the same: in all four factors, social media played an important role in developing Chinese students' intercultural awareness.

\section{Conclusion}

As no previous studies in the field of social media and intercultural communication competence focused on how Moroccan migrants use social media to improve their ICC, this paper constitutes a foretaste in this area. It focused on exploring the extent to which social media helped the Moroccan migrants established in Canada develop intercultural knowledge, attitudes, skills, and awareness of the host country through different social media tools. It thus relied on Fantini's model of ICC and based the items of the questionnaire on his scale of intercultural communication competence evaluation. However, it is also important to mention in this context that the use of the exploratory sequential design implies that this paper is naturally more qualitative than quantitative. Therefore, the rationale behind the use of the questionnaire is to reach a larger population solely.

As discussed above, the role of social media in enriching the Moroccan migrants' knowledge about the host culture was revealed to take place before migration. Social media means, namely Facebook was useful in forging relationships and friendships before migration to the country. Participants were also able to get acquainted with the Canadian culture and country through watching Youtube videos. Social media was also the main motivation behind some participants' migration. Although social media's role was revealed to be important, this study also showed that after migration, through social and face-to-face interaction, Moroccan migrants' knowledge about Canada was improved and developed. In this area, exploring Moroccan migrants' views on the role of social media in their ICC showed that the former only partially contributed to their intercultural knowledge of the host country. In terms of intercultural skills, attitudes, and awareness, social media and face-to-face interaction were proven to play a complementary role in improving the Moroccan migrants' intercultural communication competence. The present study has limitations. As the role of social media in developing Moroccan migrants' intercultural communication competence remains an unexplored area, this study can be considered an introduction in the field. While this paper relied on qualitative interpretation of results, future research to be done in this domain will have to consider the more specific evaluation and assessment tools to complement the results presented in this study.

Funding: This research received no external funding.

Acknowledgments: We thank our Moroccan compatriots in Canada for their support, availability, and contribution to the making of this paper.

Conflicts of Interests: The researcher declares no conflicts of interest. 


\section{References}

[1] Byram, M. (2000). Assessing Intercultural Competence in Language Teaching. Sprogforum, 18(6), 8-13.

[2] Creswell, J. W. 2014. Research design: Qualitative, Quantitative, and Mixed Methods Approaches. Los Angeles: SAGE publications.

[3] Deardorff, D.K. (2006). Identification and Assessment of Intercultural Competence as a Student Outcome of Internationalization. Journal of Studies in International Education. 10(3), 241-266.

[4] Fantini, A. (2000). A Central Concern: Developing Intercultural Competence. About Our Institution, 25-42.

[5] Fantini, A. (2007). Exploring and Assessing Intercultural Competence. Washington University, USA. Sprogforum. 18(6), 8-13.

[6] Günçavdı, G. Polat, S. (2016). Level of Intercultural Competence of International Students at Kocaeli University. Universal Journal of Educational Research, 4(12A), 39 - 45. DOI: 10.13189/ujer.2016.041306.

[7] Liu, M. (2019). Impact of Social Media on Intercultural Communication Competence. School of Electrical Engineering and Computer Science.

[8] Luthfia, A. Rosidah, R. Sofian, F.A. (2019). Role of Social Media in Improving Intercultural Communication Competence: A Comparative Study of European Students in Indonesia and Indonesian Students in Europe. Pertanika Journal of Social Science and Humanities.

[9] Martin, J.N. Nakayama, T.K. (2004). Intercultural Communication in Contexts. New York: McGraw Hill.

[10] Sawyer, R. Chen, G.M. (2012). The Impact of Social Media on Intercultural Adaptation. Intercultural Communication Studies.

[11] Stockinger, P. (2005, March, 10th). Intercultural Communication: A General Introduction. North Atlantic Treaty Organization. Conference paper, Roma. 